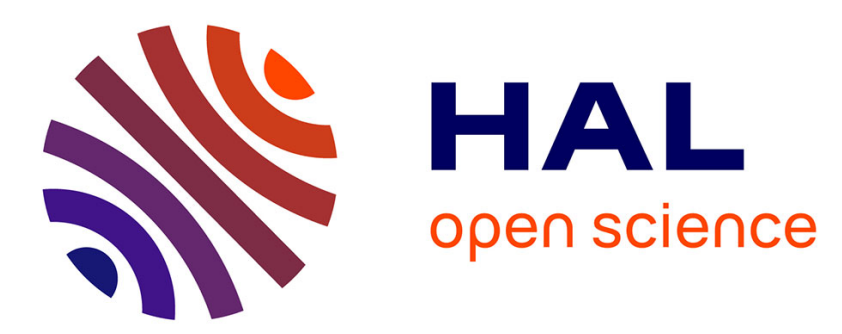

\title{
On the relation between the Luders deformation and grain boundary structure in aluminium alloy
}

\author{
Yu. B. Timoshenko
}

\section{To cite this version:}

Yu. B. Timoshenko. On the relation between the Luders deformation and grain boundary structure in aluminium alloy. Revue de Physique Appliquée, 1990, 25 (10), pp.1001-1004. 10.1051/rphysap:0199000250100100100 . jpa-00246265

\section{HAL Id: jpa-00246265 https://hal.science/jpa-00246265}

Submitted on 1 Jan 1990

HAL is a multi-disciplinary open access archive for the deposit and dissemination of scientific research documents, whether they are published or not. The documents may come from teaching and research institutions in France or abroad, or from public or private research centers.
L'archive ouverte pluridisciplinaire HAL, est destinée au dépôt et à la diffusion de documents scientifiques de niveau recherche, publiés ou non, émanant des établissements d'enseignement et de recherche français ou étrangers, des laboratoires publics ou privés. 


\title{
On the relation between the Luders deformation and grain boundary structure in aluminium alloy
}

\author{
Yu. B. Timoshenko \\ Institute for Metals Superplasticity Problems, U.S.S.R. Academy of Sciences, Ufa 450001, U.S.S.R.
}

(Received 5 October 1989, revised 18 May 1990, accepted 8 June 1990)

\begin{abstract}
Résumé. - Le durcissement de l'alliage AlMg6 à grains fins a été étudié à température ambiante après une déformation superplastique à différentes vitesses suivie d'un recuit. A partir d'observations en microscopie électronique, de la mesure de la limite d'élasticité et de l'analyse de la courbe d'écrouissage, on peut montrer que la déformation superplastique en régimes II et III modifie la structure de l'alliage et empêche l'absorption des dislocations par les joints de grains. De la même façon, lorsque la structure des joints est une structure d'équilibre, comme on l'observe après recuit et déformation en régime $I$, l'absorption et la création de dislocations aux joints sont facilitées, ce qui provoque une déformation par bandes de Lüders.
\end{abstract}

\begin{abstract}
Strain hardening of the fine grained AlMg6 alloy at room temperature was studied after the alloy annealing and preliminary superplastic deformation (SPD) at different strain rates. Electron microscopy, measurements of conventional yield stress, and strain hardening analysis indicated that SPD in regions II and III, corresponding to optimal and higher strain rates respectively, transformed the alloy into a state which prevented lattice dislocations from running into grain boundaries. At the same time, the equilibrium state of grain boundaries observed after annealing in state I (low strain rates), facilitates the generation and running of dislocations into grain boundaries and provides for the Luders deformation.
\end{abstract}

\section{Introduction.}

During SPD, intergranular and grain boundary processes are known to develop simultaneously [1]. They are closely related, which is expressed in the interaction of lattice dislocations with grain boundaries, which results in the grain boundary nonequilibrium. As compared with equilibrium boundaries, non-equilibrium [2] boundaries have quite different effect on the behaviour of alloys since they are of a higher energy and mobility. The nonequilibrium structure of grain boundaries significantly influences the deformation behaviour [4].

The purpose of this paper is to evaluate experimentally the non-equilibrium state of grain boundary structure and its effect on the aluminium alloy strain hardening.

\section{Experimental procedure.}

The AlMg6 (Al-6.0\% Mg-0.6\% Mn) alloy was used for the investigation. This alloy with the grain size of $6 \mu \mathrm{m}$ displays SP behaviour at $693 \mathrm{~K}$ [5].
To determine the grain boundary state, the conventional yield stress, $\sigma_{0.2}$, was measured, its value considerably increasing with the growth of grain boundary non-equilibrium [6]. The stress-strain curves at room temperature were also considered.

Prior to tension at room temperature, the alloy samples were subjected to upsetting under SP conditions $(\varepsilon=15 \%)$ at different strain rates and then quenched in water. Mechanical testing was performed on an INSTRON testing machine. Electron microscopy was performed on a TESLA BS-540 microscope.

\section{Results.}

The flow stress curve and strain rate sensitivity coefficient, $m$, of the alloy under study are shown in figure 1a. SP features can be observed in a wide range of strain rates, the optimum interval being $10^{-4} / 10^{-3} \mathrm{~s}^{-1}$ and the maximum value of the strain rate sensitivity coefficient being :

$$
m=\frac{\mathrm{d} \log \sigma}{\mathrm{d} \log \dot{\varepsilon}}=0.43
$$


As well as in other alloys, there can be distinguished three characteristic regions of SP behaviour in the alloy. Figure $1 \mathrm{~b}$ shows the $\sigma_{0.2}$ curve for samples pre-strained under SP conditions and at different strain rates.

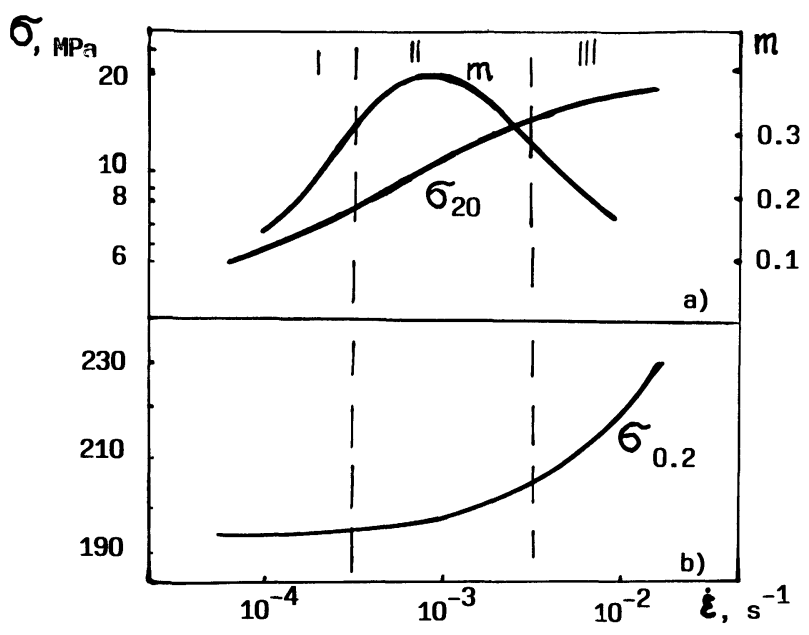

Fig. 1. - Dependence of flow stress, $\sigma_{20}$, strain rate sensitivity factor, $m$, at $T=693 \mathrm{~K}$ (a) and conventional yield stress, $\sigma_{0.2}$, at $T=293 \mathrm{~K}$ (b) on the SPD rate, $\dot{\varepsilon}$, of the AlMg6 alloy.

Metallographic analysis proved that no remarkable microstructural changes took place after the $15 \%$ straining. After straining at low and optimum rates (regions I and II), the values of $\sigma_{0.2}$ in both the regions are similar and approximately correspond to the yield stress values obtained for the as-annealed alloy $(200 \mathrm{MPa})$. But at higher strain rates (region III) the yield stress increases and the greater the pre-strain rate, the larger the yield stress. Note that similar results were obtained for the $\mathrm{Pl}-5 \% \mathrm{Cd}$ alloy [7] whose mechanical properties were tested after SPD.

The analysis of stress-strain curves (Fig. 2) indicates that the alloy behaviour after pre-straining in region I is similar to that of the annealed material. The stress-strain curve is characterized by the presence of creep regions without any traces of hardening (the Luders deformation) at strain levels less than $1 \%$. But after deformations at optimum and higher strain rates, such creep regions are not observed, hardening taking place once the conventional yield stress has been achieved. Note that creep regions without hardening appeared on a curve illustrating the behaviour of samples strained at an optimum rate, but then slowly cooled down to room temperature.

The study of the alloy structures after $1 \%, 3 \%$ and $5 \%$ straining which correspond to different fragments of the stress-strain curve allowed to define

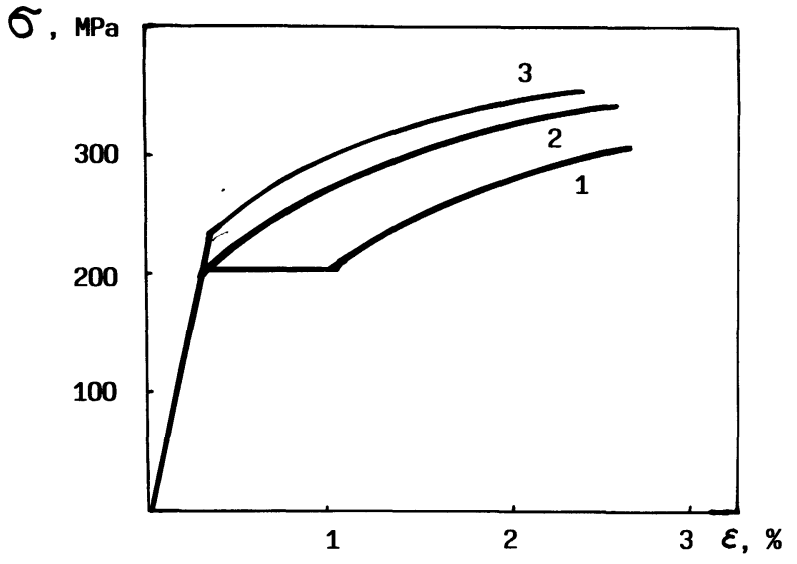

Fig. 2. - Flow-stress-strain curves of the alloy at room temperature after annealing at $T=693 \mathrm{~K}$ for $10 \mathrm{~min}$ (curve 1) and after preliminary SP deformation, $\varepsilon=15 \%$ and $\dot{\varepsilon}=1.4 \times 10^{-3} \mathrm{~s}^{-1}$ (curve 2), and $\dot{\varepsilon}=1.4 \times 10^{-1} \mathrm{~s}^{-1}$ (curve 3).

the following features of the dislocation structure evolution. After the $1 \%$ straining, only individual lattice dislocations are observed, no pile-ups and tangles being formed (Fig. 3a).

Since room temperature is very similar to the temperature of relaxation of these defects, the density can be determined by the variation of the boundary diffraction contrast. The fact that these defects lie immediately within the grain boundaries, but not in their vicinity is confirmed by diffraction experiments: images of these dislocations are in contrast during the image formation in the reflexions of each of the two adjacent grains. When the strain level grows up to $3 \%$, the density of trapped lattice dislocations and lattice dislocations considerably increases. In the vicinity of triple points, the boundary banded contrast disappears (Fig. 3b). Areas with a high local density of lattice dislocations appear within the grains.

The lattice dislocation tangles are formed when grain boundaries have been already packed with lattice dislocations (Fig. 3c).

\section{Discussion.}

Electron microscopic studies and texture analysis [1] indicate that dislocation sliding takes place in all the three regions of superplastic flow. The density of extrinsic grain boundary dislocations formed during the interaction of lattice dislocations and grain boundaries [6] increases with the growth of strain rate.

After spreading of extrinsic grain boundary dislocations, non-equilibrium grain boundaries are formed [2] that is why the value of non-equilibrium must be proportional to strain rate. However, this conclusion does not agree with the obtained exper- 

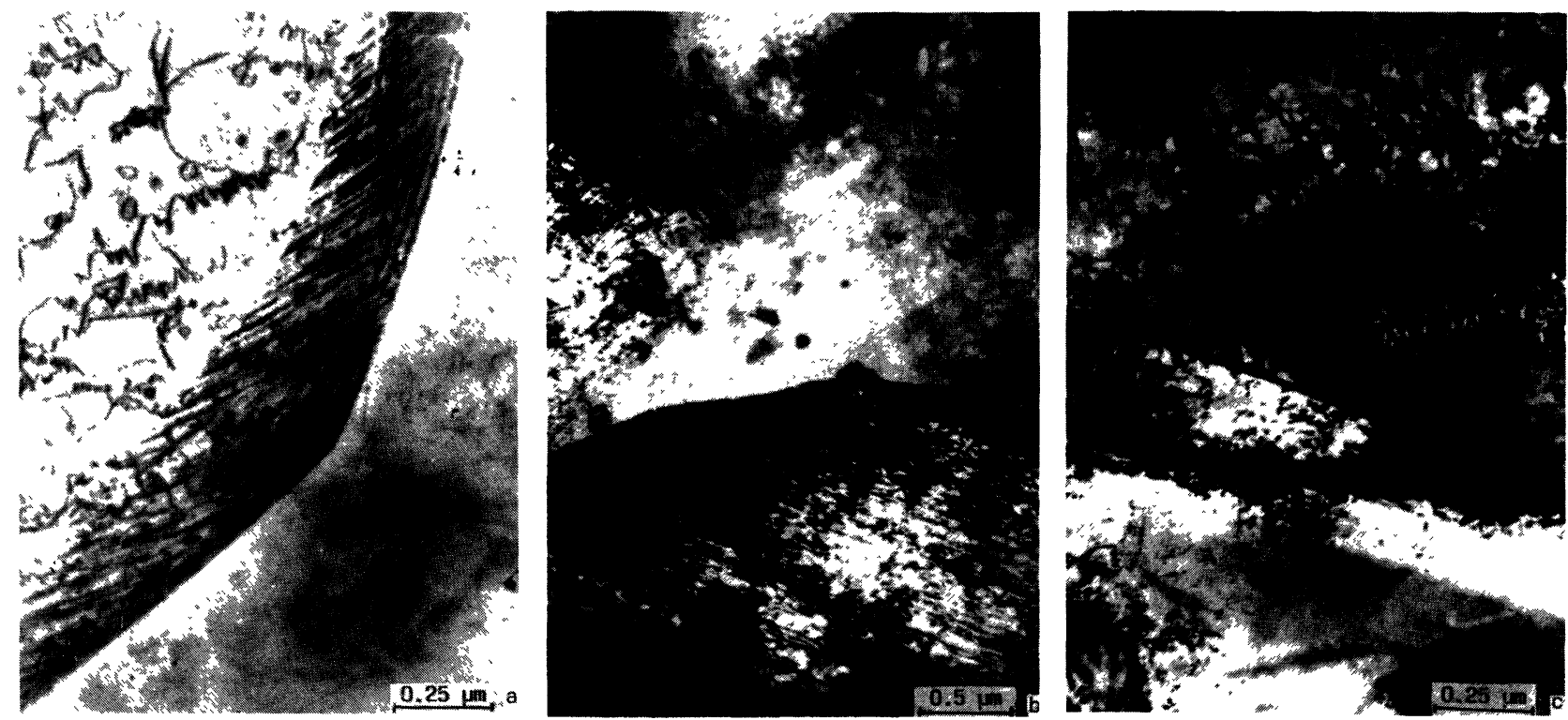

Fig. 3. - The AlMg6 alloy structure after annealing at $693 \mathrm{~K}$ and deformation at $293 \mathrm{~K}, \varepsilon=1 \%$ (a), $\varepsilon=3 \%$ (b), and $\varepsilon=5 \%(\mathrm{c})$.

imental data. The yield stress value of the alloy after SPD at low and optimal rates is equal to $\sigma_{0.2}$ of the annealed material. Such a discrepancy can be explained by active recovery processes which are in progress in regions I and II and reduce the nonequilibrium value. Grain migration and grain boundary sliding can act as such processes. In [3] it was shown that on the one hand the grain boundary nonequilibrium enhanced the migration of grains and on the other hand migration reduced the value of nonequilibrium. Grain boundary sliding making a significant contribution to the total deformation on region II results in the rearrangement of the atomic structure of grain boundaries and can also reduce the value of non-equilibrium. At the same time, the non-equilibrium structure of grain boundaries stimulates sliding along the boundaries [4]. These processes, probably, account for the yield stress not increasing after the flow stress is over in regions I and II.

During deformation in region III, the contribution of grain boundary sliding to the total strain sharply decreases, dislocations being actively accumulated both within the grains and in grain boundaries, and, consequently, the value of yield stress increases.

SPD in region III, without changing the yield stress of as-annealed material, considerably influences hardening during cold deformation (Fig. 2). In [8] it was suggested that the existence of deformation stages without hardening was not the result of the interaction of the dissolved material atoms and dislocations, but is connected with the growing contribution and homogeneity of the Luders deformation when the grain size diminishes. It was also suggested that this effect is connected with the interaction between lattice dislocations and grain boundaries. It was established [4] that strain hardening in polycrystals was mainly determined by the grain boundary type and state, particularly, by the presence of trapped lattice dislocations. The influence of trapped lattice dislocations on the deformation behaviour is expected to be especially strong in fine grained materials where the total length of grain boundaries is large and the majority of the released lattice dislocations passes freely through the grain body and is trapped in the opposite boundary.

\section{Conclusions.}

Preliminary SPD in regions II and III transforms the alloy into a state which prevents lattice dislocations from running into grain boundaries in the course of subsequent cold straining. At the same time, the generation and sinking of dislocations is facilitated in a fine grained alloy with equilibrium boundaries, which is observed in the alloy after annealing and SPD in region I. The above conclusions are confirmed by the electron microscopy analysis of grain boundary structure, evaluation of yield stress, and nature of strain hardening. The grain boundary equilibrium and free sinking of lattice dislocations into them provide for the Luders deformation taking place in the fine grained aluminium alloy. 


\section{References}

[1] KaibysheV O. A., Superplasticity of Commercial Alloys, Moscow : Metall. Publ. (1984) (in Russian).

[2] Valiev R. Z. et al., Phys. Stat. Sol. (a) 77 (1983) 97.

[3] VAliev R. Z. et al., Fiz. Tverdago Tela (1980) 2213 (in Russian).

[4] Valiev R. Z. and Kaibyshev O. A., Doklady Akad. Nauk SSSR 253 (1981) 91 (in Russian).
[5] Valiev R. Z. et al., Fiz. Metal. Metal. 51 (1981) 615 (in Russian).

[6] Gertsman V. Yu. et al., Poverkhnost, Fiz. Khim. Mekh. 4 (1986) 138 (in Russian).

[7] Alden T. H., Trans. ASM 61 (1968) 559.

[8] Wyrzykowski J. W. and Grabski M. W., Mat. Sci. Eng. 56 (1982) 197. 